\title{
Impact of intraspecific competition on photosynthetic apparatus efficiency in potato (Solanum tuberosum) plants
}

\author{
J. OLECHOWICZ*, C. CHOMONTOWSKI*, P. OLECHOWICZ ${ }^{* *}$, S. PIETKIEWICZ*, A. JAJOO ${ }^{* * *,+}$, \\ and M.H. KALAJI ${ }^{* * * * *,+}$
}

Department of Plant Physiology, Warsaw University of Life Sciences SGGW, Warsaw, Poland*

Cardinal Stefan Wyszyński University in Warsaw, Warsaw, Poland ${ }^{* *}$

School of Life Science, Devi Ahilya University, Indore 452018, India ${ }^{* * *}$

SI Technology, Górczewska 226C/26, 01-460 Warsaw, Poland ${ }^{* * * *}$

\begin{abstract}
Unfavourable growth conditions significantly determine the yield of crop plants. Intraspecific competition is a condition in which plants compete with each other for environmental resources. An excessive density contributes to increased competition within species, which results in disruption of photosynthesis process. According to this idea, experiments were conducted to investigate the photosynthetic response of potato (Solanum tuberosum) plants to excessive congestion. Two potato varieties of different earliness classes (Vineta and Satina) were used to evaluate the efficiency of the photosynthetic apparatus based on chlorophyll (Chl) fluorescence measurements under stress conditions. Changes in Chl contents of the tested plants were also analysed. In relation to intraspecific competition, we can conclude that the Vineta variety was less sensitive to this stress factor. In contrast, the photosynthetic apparatus of the Satina variety showed less efficient functioning under these conditions. In this study, the application of Chl fluorescence was presented for the first time in order to analyse the effects of intraspecific competition in plants.
\end{abstract}

Additional key words: chlorophyll fluorescence transient; intraspecific competition; performance index; photosystem II efficiency.

\section{Introduction}

Potato (Solanum tuberosum L.) is grown in $80 \%$ of the world's countries. Nevertheless, according to Blum et al. (1988), only $10 \%$ of agricultural land conditions are optimal for the growth and development of this plant. Adverse environmental conditions interfere with the plant life processes, and can cause even death in extreme cases (Germ 2008). On the other hand, according to Schulze et al. (2002), stress factors are the basis for the positive selection of plants. Under adverse environmental conditions, only organisms with high resistance and rapid adaptation to the changes can survive.

Higher plants compete with each other for limited environmental resources, such as micronutrients, macronutrients, water, space, and sunlight. Individuals belonging to the same species have similar life requirements, therefore, an intraspecific competition has a stronger character compared to interspecies competition (Mangla et al. 2011). Negative impacts occurring between plants contribute to a diversity in a size and shape of individuals and a decline in the size, reproduction, and survival rate of the population (Weigelt and Jolliffe 2003). Only the strongest individuals have a chance to survive and produce offsprings (Mangla et al. 2011). Plants with rapid growth, highly developed root systems, lush foliage, and a secretion of allelochemicals into external environments significantly hamper access to the limited environmental resources. As a result, the growth and development of potential rivals is inhibited, caused by changes in the course of basic life processes, especially photosynthesis.

An analysis of life functions, such as photosynthesis, allows a determination of the degree of a plant's resistance to adverse environmental conditions, such as excessive congestion. Measurement of a relative $\mathrm{Chl}$ content is commonly used to assess the physiological state of plants. The loss of pigments proves not only plant aging, but also the influence of long-term stress (Netto et al. 2005). In the

Received 9 November 2016, accepted 20 February 2017, published as online-first 18 April 2017.

${ }^{+}$Corresponding authors; e-mails: hazem@kalaji.pl, anjanajajoo@hotmail.com

Abbreviations: Area - area above chlorophyll fluorescence induction curve; $\mathrm{F}_{0}$ - minimal fluorescence; $\mathrm{F}_{\mathrm{m}}$ - maximal fluorescence; $\mathrm{F}_{\mathrm{v}}$ - variable fluorescence; $\mathrm{F}_{\mathrm{v}} / \mathrm{F}_{\mathrm{m}}$ - maximal photochemical efficiency of PSII; PI - performance index; $t_{\mathrm{FM}}$ - time to reach maximal chlorophyll fluorescence.

(C) The Author(s). This article is published with open access at link.springer.com 
same way, measurement of $\mathrm{Chl}$ fluorescence has been used more and more often for the evaluation of photosynthetic apparatus activity under both normal and stress conditions (e.g. competition) (Kalaji et al. 2016). Analysis of Chl fluorescence parameters provides information about the condition of the photosynthetic apparatus, allowing changes in the photosynthesis process to be detected before they are evident in the physical appearance of plants

\section{Materials and methods}

Plants: Two varieties of potato were analysed: Vineta (early variety, stalk-foliar morphotype) and Satina (medium early variety, stalk-foliar morphotype). Plants were grown under competitive conditions for environmental resources caused by congestion. One, four or five clippings of seed potatoes (mass approx. 7-8 g) with welldeveloped sprouts were placed in pots $(14.5 \times 15 \mathrm{~cm})$. The substrate consisted of a soil mixture, sand, and peat $(2: 1: 1$; $\mathrm{v}: \mathrm{v}: \mathrm{v})$, which was blended with modified Hoagland culture medium. Substrate moisture content was maintained at $60 \%$ of field water capacity. The experiment was carried out in phytotron (Forclean, ZALMED Ltd., Poland) chambers. Diversified conditions prevailed during the day in terms of temperature $\left(\mathrm{min} / \max\right.$ of $\left.15 / 21^{\circ} \mathrm{C}\right)$, light intensity (maximum about $300 \mu \mathrm{E} \mathrm{m}^{-2} \mathrm{~s}^{-1}$ ) and humidity $(\mathrm{min} / \mathrm{max}$ of $50 / 65 \%)$. Measurements of relative $\mathrm{Chl}$ content and $\mathrm{Chl}$ fluorescence were performed throughout the experiment. Three experimental setups were as follows: one plant in a pot (T1; control), four plants in a pot (T2), five plants in a pot (T3). In T3, separate measurements were performed on plants at the edge (T3edge) and on the plant in the centre of the pot (T3-centre) (Fig. 1S, supplement available online).

Relative Chl content: The measurements were performed by using a Chl meter (SPAD-502, Minolta Co., Japan). The relative $\mathrm{Chl}$ content of leaves was determined three times on four plants from each combination. Measurements were performed on three areas of the plant (top, middle, and bottom). Three leaves were analysed for each area and the results were averaged $(n=96)$.

Chl fluorescence: Photosynthetic efficiency was determined using a plant efficiency analyser fluorimeter (Handy-PEA, Hansatech Instruments Ltd., UK). Measure-

\section{Results}

Relative Chl content: During the first measurement of the Vineta variety (Fig. 1A), the greatest relative Chl content was observed in the middle of the canopy (T3-centre) and then in the control plants (T1). The T1 plants showed a high, but constant $\mathrm{Chl}$ content until $56 \mathrm{~d}$ and then increased. T2 plants showed an increase in the Chl content during the growing season and became constant after $56 \mathrm{~d}$.
(Kalaji et al. 2011). The aim of this study was first to compare the efficiency of the photosynthetic apparatus of two varieties of potato plants (Solanum tuberosum L.) growing under conditions of competition for environmental resources caused by congestion, and second to find out whether the measurement of Chl fluorescence is a suitable tool for such a study.

ments were performed on dark-adapted plant material (approximately $30 \mathrm{~min}$ ) and were carried out three times on four plants from each combination. The measurements were performed on three leaves from the top, middle, and bottom of the plant; results were averaged $(n=96)$. The following parameters were recorded during the study: $\mathrm{F}_{0}$ and $F_{m}, F_{v} / F_{m}, t_{F M}, P I$, and Area, where $F_{0}$ is the minimal fluorescence, $F_{m}$ is the maximal fluorescence, $F_{v}$ is the variable fluorescence, $F_{v} / F_{m}$ is the maximal photochemical efficiency of PSII, PI is the performance index, and $t_{\mathrm{FM}}$ stands for the time to reach maximal $\mathrm{Chl}$ fluorescence and its value is higher when electron transport is blocked somewhere (Marler and Lawton 1994, Strasser et al. 2000). Minimum fluorescence, $F_{0}$, is defined as the fluorescence, when all reaction centres (RCs) of PSII are open, i.e. when the first electron acceptor of PSII, $\mathrm{Q}_{\mathrm{A}}$, is oxidized. Maximum fluorescence $\left(\mathrm{F}_{\mathrm{m}}\right)$ is defined as the fluorescence when all the PSII RCs are closed, i.e. when all $Q_{A}$ is reduced. An increase in the $F_{0}$ value may occur due to many combined processes, such as functional disconnection of LHCII from the PSII complex or accumulation of inactive RCs (Mathur et al. 2011). The Area above the fluorescence curve between $F_{0}$ and $F_{m}$ is proportional to the pool size of the electron acceptors $\mathrm{Q}_{\mathrm{A}}$ on the reducing side of PSII.

Statistical evaluation: The experiment was established in a totally random system with four replications $(n=4)$ analysing the effect of the potato variety $(a=2)$, the method of planting $(b=4)$, and the measuring time $(c=3)$ on the relative $\mathrm{Chl}$ content and $\mathrm{Chl}$ fluorescence $(n=96)$. The results were statistically analysed using analysis of variance (ANOVA), averages of multiple comparisons were determined by a Tukey's test (STATGRAPHICS Centurion XVI.I).

T3-edge plants showed very high values at the beginning, but gradually declined during growth. T3-centre plants showed a gradual increase during the growing season.

In contrast, the lower $\mathrm{Chl}$ content was found in $\mathrm{T} 2$ and T3-edge plants. However, at the end of the growing season, an increase in the $\mathrm{Chl}$ content occurred in $\mathrm{T} 1$ plants and in the plants at the edge of the canopy (T2 and 
T3-edge). The reverse situation occurred in individuals growing in the centre of a group of five plants (T3-centre). In the Satina variety, the greatest relative content of $\mathrm{Chl}$ in leaves was exhibited by the T1 control plants; wherein during the growing season the Chl content gradually decreased. A similar situation was observed in the pot with four plants (T2). In contrast, in the plants growing at the edge of the canopy (T3-edge), there was a decrease and subsequently an increase in the relative Chl content. The relative content of Chl remained similar in the plants planted in the middle of the canopy throughout the experiment (T3-centre) (Fig. 1B).

Based on statistical analysis, we found that the plant variety and the planting method both showed a significant impact on relative $\mathrm{Chl}$ content, in contrast to the measurement time. The effect of interaction occurred between the variety and combination, variety and measurement time, and variety and combination and measurement time. The potato varieties differed significantly in terms of test variable; Vineta was characterised by higher relative $\mathrm{Chl}$ content than that of Satina $\left(\operatorname{LSD}_{\alpha=0.05}=2.25\right)$. Individuals unthreatened by competition were characterised by the higher content of the Chl in other combinations, however, there were no significant differences $\left(\operatorname{LSD}_{\alpha=0.05}=4.19\right)$.

Chl fluorescence: Several important parameters, such as $\mathrm{F}_{0}, \mathrm{~F}_{\mathrm{m}}, \mathrm{F}_{\mathrm{v}} / \mathrm{F}_{\mathrm{m}}, \mathrm{t}_{\mathrm{FM}}$, Area, and PI were calculated from $\mathrm{Chl}$ fluorescence measurements.

After $35 \mathrm{~d}$, plants of Vineta growing in congestion showed reduced values of $\mathrm{F}_{0}, \mathrm{t}_{\mathrm{FM}}$, and PI. In comparison with the control plants, there was an increase in $\mathrm{F}_{0}$, Area, and $\mathrm{t}_{\mathrm{FM}}$ (except for plants growing in the middle of the canopy) (Fig. 2A). There was a significant decrease in PI in the plants grown in congestion. During the growing season, intraspecific competition contributed to the increase in $\mathrm{F}_{0}$, a reduction in Area and a reduction in the $t_{\mathrm{FM}}$ factor (Fig. 2B). At $77 \mathrm{~d}$, there was a significant increase in the value of the PI (Fig. $2 C$ ) and a decrease in

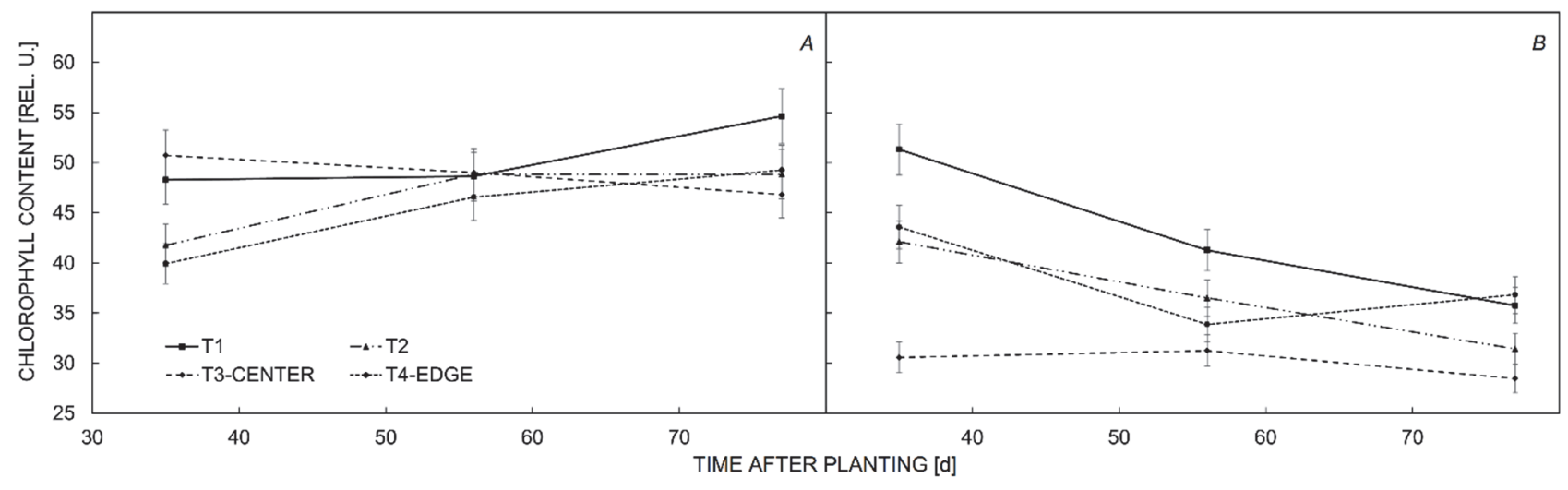

Fig. 1. Change in relative chlorophyll content in leaves of Vineta $(A)$ and Satina $(B)$ planted individually (control T1) and in congestion (T2 - four plants, T3-centre - central plant of five plants, T3-edge - plants at edges of a group of five plants). Measurements were performed 35, 56, and 77 days after planting. Data are means $\pm \mathrm{SE}$.

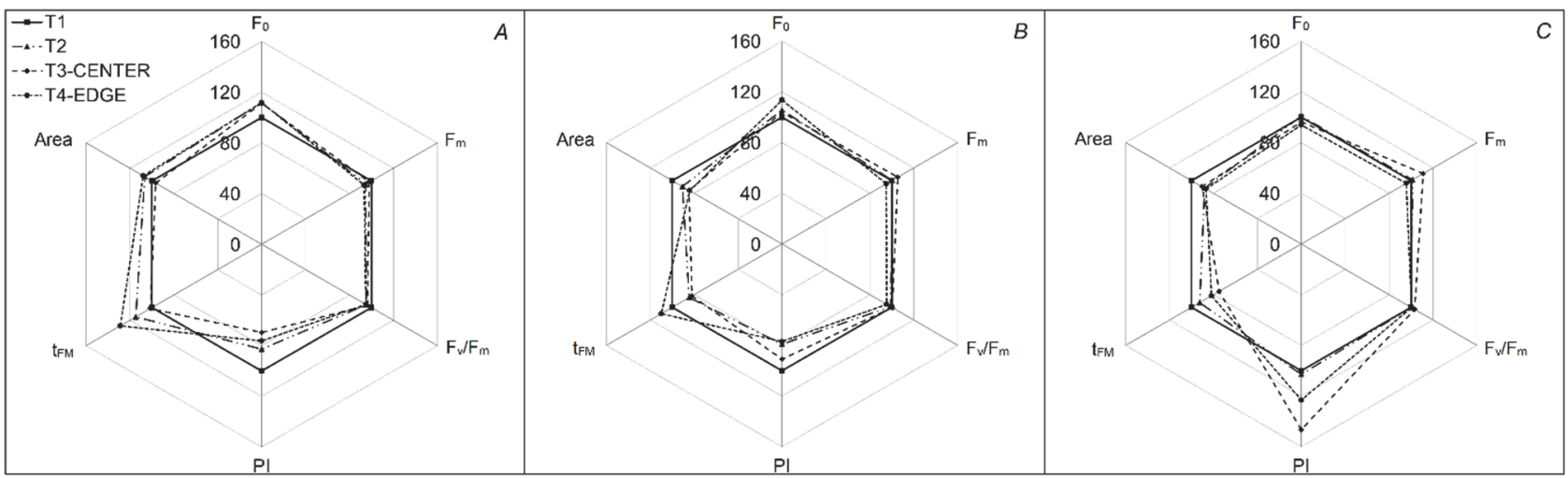

Fig. 2. Changes in value of chlorophyll fluorescence parameters in leaves of the Vineta variety planted individually (control T1) and in congestion (T2 - 4 plants, T3-centre - central plant of five plants, T3-edge - plants at edges of a group of five plants). The measurements were performed $35(A), 56(B)$, and $77(C)$ days after planting. The results are given as percentage of control, $P<0.005$. Area - area above chlorophyll fluorescence induction curve; $F_{0}$ - minimal fluorescence; $F_{m}$ - maximal fluorescence; $F_{v} / F_{m}-$ maximal photochemical efficiency of PSII; PI - performance index; $\mathrm{t}_{\mathrm{FM}}$ - time to reach maximal chlorophyll fluorescence. 


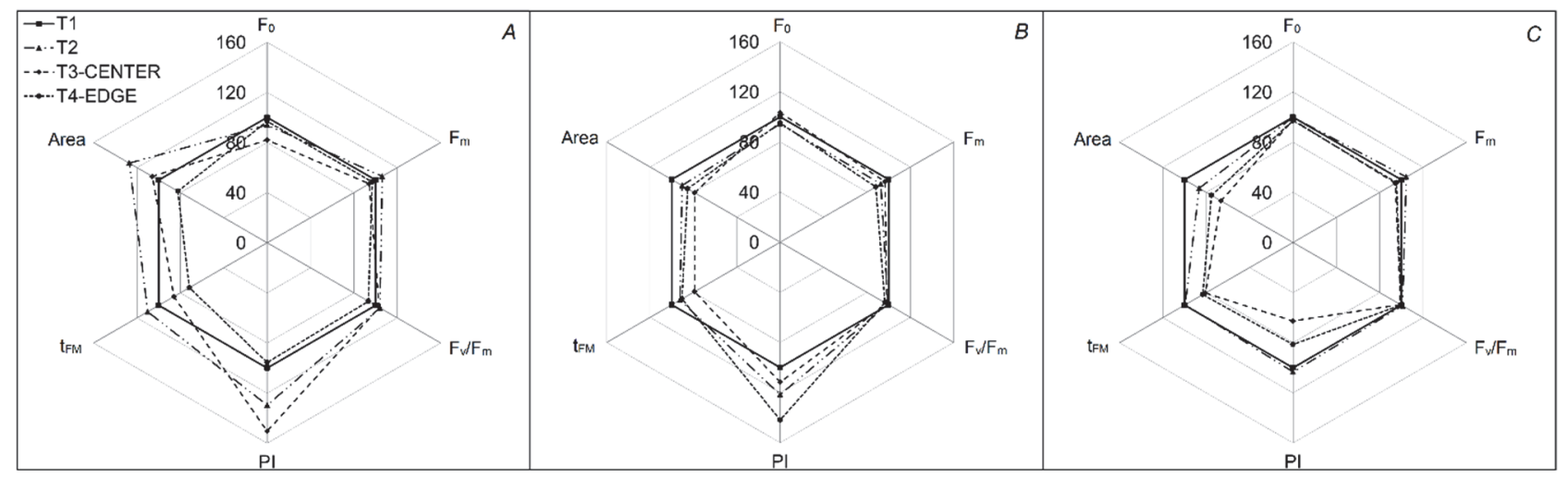

Fig. 3. Changes in the value of chlorophyll fluorescence parameters in leaves of the Satina variety planted individually (control T1) and in congestion (T2 - 4 plants, T3-centre - central plant of five plants, T3-edge - plants at edges of a group of five plants). The measurements were performed $35(A), 56(B)$, and $77(C)$ days after planting. The results are given as percentage of control. Area - area above chlorophyll fluorescence induction curve; $\mathrm{F}_{0}$ - minimal fluorescence; $\mathrm{F}_{\mathrm{m}}$ - maximal fluorescence; $\mathrm{F}_{\mathrm{v}} / \mathrm{F}_{\mathrm{m}}$ - maximal photochemical efficiency of PSII; PI - performance index; $\mathrm{t}_{\mathrm{FM}}$ - time to reach maximal chlorophyll fluorescence.

$t_{\mathrm{FM}}$ and Area in the plants grown in congestion as compared to T1 control plants.

In case of Satina variety, the decrease in the $\mathrm{F}_{0}$ value was observed even during the first measurement of Chl fluorescence under conditions of increased competition. The plants growing in congestion compared with the control were characterised by higher values of $\mathrm{F}_{\mathrm{m}}, \mathrm{t}_{\mathrm{FM}}$, Area, and a lower PI (Fig. $3 A$ ).

Statistical analysis indicated that the age of the plants had a significant impact on the value of all Chl fluorescence parameters measured during the experiment. The $t_{\mathrm{FM}}$ factor

\section{Discussion}

We can assume that potato plants growing in excessive congestion adopted different defensive strategies depending on the length of the growing season (earliness class) and the severity of intraspecific competition (congestion degree). The strategy of individuals from the periphery was a domination. They become a stressor factor for the plants located in the middle of the canopy by inhibiting their growth and development. A similar result was achieved by Pietkiewicz (2000), who analysed the growth rate and intensity of biomass accumulation by potato plants growing in congestion. The consequence of such long-term stress includes changes in the quantitative ratio of the photosynthetic pigments in leaf blades (Netto et al. 2005).

In control plants of medium-early varieties (no competition for limited environmental resources), the relative $\mathrm{Chl}$ content was reduced during ontogeny. In comparison to the control plants, the Chl content was lower in plants growing in congestion. Vineta variety showed the higher Chl content as compared to Satina variety. It is evident that the long-lasting stressor (excessive congestion) contributed to the reduction of $\mathrm{Chl}$ also depended on the planting method. In contrast, the interactions between the variety $\times$ measurement time and variety $\times$ measurement time $\times$ combination determined PI values. In the Vineta variety, a lower PI was found $\left(\mathrm{LSD}_{\alpha=0.05}=0.38\right)$, there was an prolonged $\mathrm{t}_{\mathrm{FM}}\left(\mathrm{LSD}_{\alpha=0.05}=\right.$ $40.58)$ and an increase in Area $\left(\operatorname{LSD}_{\alpha=0.05}=4489.16\right)$ compared to the plants of the Satina variety. In contrast, the lowest value of the $t_{\mathrm{FM}}$ was obtained by the plants planted at the centre of the canopy, the longest $t_{\mathrm{FM}}$ factor was achieved by individuals, not threatened by competition $\left(\mathrm{LSD}_{\alpha=0.05}=75.71\right)$.

content in leaf blades of the plants studied.

Adverse environmental conditions lead to a decrease in photochemistry resulting in an increase in the intensity of Chl fluorescence. Monitoring Chl fluorescence can help obtain information about the efficiency of the photochemical processes (Kalaji and Loboda 2007). To our knowledge, the application of Chl fluorescence for analysing effects of the intraspecific competition was presented for the first time in this paper.

During the experiment, a decrease in $\mathrm{F}_{\mathrm{m}}$, a reduction in Area, and a shortening of the $t_{\mathrm{FM}}$ value were found in the Satina variety growing in the middle and at the edge of the canopy. There was also a reduction in PI. Other parameters were only slightly altered during the plant development. The provision of potato plants (variety ILS19) with 9.0 $\mathrm{mM} \mathrm{Fe}$ and Hoagland growing medium contributed to an increase in $\mathrm{F}_{0}, \mathrm{~F}_{\mathrm{m}}$, and PI (Adamski et al. 2012). At the same time, it was found that water scarcity and high light intensity [above $300 \mu \mathrm{mol}\left(\right.$ photon) $\mathrm{m}^{-2} \mathrm{~s}^{-1}$ ] caused an increase in $\mathrm{F}_{0}$ and a decrease in $\mathrm{F}_{\mathrm{m}}$ in potato plants of the Kufri Sindhuri variety (Basu et al. 1998). Numerous studies have shown that under unfavourable environmental 
conditions, the potato plant genotype determines the course of Chl fluorescence induction (Lin et al. 2007). In the case of the $F_{v} / F_{m}$, no significant differences occurred between the varieties. As the most commonly used Chl $a$ fluorescence parameter, $\mathrm{F}_{\mathrm{v}} / \mathrm{F}_{\mathrm{m}}$ represents the conversion and capture efficiency of primary light energy and is an excellent measure for the evaluation of quantum yield of primary photochemistry of PSII. This parameter decreases gradually with prolonged duration of the stressor. A similar effect was observed by Razinger et al. (2012). However, according to Oukarroum et al. (2007), evaluation of the efficiency of PSII exclusively on the basis of the $F_{v} / F_{m}$ parameter is insufficient. For a more detailed analysis of plant response to the stressor, it is necessary to take into account the functioning of PSII (PI). The efficiencies and specific fluxes also determine the photosynthetic performance index $\left[\mathrm{PI}_{\text {total }}\right]$, which is therefore sensitive to changes in either antenna properties, trapping efficiency or electron transport beyond $\mathrm{Q}_{\mathrm{A}}$ (Kalaji et al. 2016; Mathur et al. 2016). Chl fluorescence parameter analysis revealed that the tested genetic characteristics of the potato varieties also influenced the plant photosynthetic activity, especially the value of PI. Michałek and Sawicka (2002) argue that the genotype largely determines the efficiency of the photosynthetic apparatus, thereby affecting the measurement of $\mathrm{Chl}$ fluorescence.

Conclusions: The measurement of Chl fluorescence can be successfully used to assess the photosynthetic efficiency for potato plants competing with each other for limited environmental resources. At the same time, contrary to many previously conducted experimental works, measuring the $F_{v} / F_{m}$ parameter was insufficient to assess the efficiency of the PSII in plants growing in congestion. However, the analysis of changes in the value of PI and the measurement of relative $\mathrm{Chl}$ content revealed that the Vineta variety was more resistant to the stress conditions than the Satina variety. The results provide a basis for applications of $\mathrm{Chl}$ fluorescence measurement as a tool to identify potato varieties tolerant to excessive congestion.

Open Access This article is distributed under the terms of the Creative Commons Attribution License which permits any use, distribution, and reproduction in any medium, provided the original author(s) and the source are credited.

\section{References}

Adamski J.M., Danieloski R., Deuner S. et al:: Responses to excess iron in sweet potato: impacts on growth, enzyme activities, mineral concentrations, and anatomy. - Acta Physiol. Plant. 34: 1827-1836, 2012.

Basu P.S., Sharma A., Sukumaran N.P.: Changes in net photosynthetic rate and chlorophyll fluorescence in potato leaves induced by water stress. - Photosynthetica 35: 13-19, 1998.

Blum A., Mayer J., Golan G.: The effect of grain number (sink size) on source activity and its water - relations in wheat. $-\mathrm{J}$. Exp. Bot. 39: 106-114, 1988.

Germ M.: The response of two potato cultivars on combined effects of selenium and drought. - Acta. Agric. Slov. 91: 121$137,2008$.

Kalaji M.H., Jajoo A., Oukarroum A. et al.: Chlorophyll a fluorescence as a tool to monitor physiological status of plants under abiotic stress conditions. - Acta Physiol. Plant. 38: 102, 2016.

Kalaji M.H., Bosa K., Kościelniak J. et al.: Chlorophyll a fluorescence - A useful tool for the early detection of temperature stress in spring barley (Hordeum vulgare L.). Integr. Biol. 15: 925-934, 2011.

Kalaji M.H., Loboda T.: Photosystem II of barley seedlings under cadmium and lead stress. - Plant Soil Environ. 53: 511-516, 2007.

Lin K.H., Hwang W.C., Lo H.F.: Chilling stress and chilling tolerance of sweet potato as sensed by chlorophyll fluorescence. - Photosynthetica 45: 628-632, 2007.

Mangla S., Sheley R.L., James J.J. et al.: Intra and interspecific competition among invasive and native species during early stages of plant growth. - Plant Ecol. 212: 531-542, 2011.

Marler T., Lawton P.: Error in interpreting field chlorophyll fluorescence. The $\mathrm{F}_{0}$ increase measurements: heat gain from solar radiation. - HortScience 29: 1172-1174, 1994.

Mathur S., Kalaji H.M., Jajoo A.: Investigation of deleterious effects of chromium phytotoxicity and photosynthesis in wheat plant. - Photosynthetica 54: 185-192, 2016.

Mathur S., Singh P., Mehta P. et al:: A comparative study to evaluate the effects of high temperature and low $\mathrm{pH}$ on PSII photochemistry in spinach thylakoid membranes. - Biol. Plantarum 55: 747-751, 2011.

Michałek W., Sawicka B.: Chlorophyll content and photosynthetic activity of medium-late potato cultivars in centraleast Poland field conditions. - Acta Agroph. 6: 183-195, 2005.

Netto A.T., Campostrini E., de Oliveira J.G. et al.: Photosynthetic pigments, nitrogen, chlorophyll $a$ fluorescence and SPAD-502 readings in coffee leaves. - Sci. Hortic.Amsterdam 104: 199-209, 2005.

Oukarroum A., El Madidi S., Schansker G. et al:: Probing the responses of barley cultivars (Hordeum vulgare L.) by chlorophyll $a$ fluorescence OLKJIP under drought stress and re-watering. - Environ. Exp. Bot. 60: 438-446, 2007.

Pietkiewicz S.: Studying the Strategy of Dry Matter Accumulation by Potato Plants (Solanum tuberosum L.) with Application Growth Analysis. Pp. 109. Warsaw University of Life Sciences, Warsaw 2000.

Razinger J., Drinovec L., Berden-Zrimec M.: Delayed fluorescence imaging of photosynthesis inhibitor and heavy metal induced stress in potato. - Cent. Eur. J. Biol. 7: 531-541, 2012.

Schulze E-D., Beck E., Müller-Hohenstein K.: Plant Ecology. Pp. 702. Springer-Verlag, Berlin 2002.

Strasser R.J., Srivastava A., Tsimilli-Michael M.: The fluorescence transient as a tool to characterize and screen photosynthetic samples. - In: Mohanty P., Yunus M., Pathre F. (ed.): Probing Photosynthesis: Mechanisms, Regulation and Adaptation. Pp. 443-480. Taylor \& Francis, London 2000.

Weigelt A., Jolliffe P.: Indices of plant competition. - J. Ecol. 91: 707-720, 2003. 